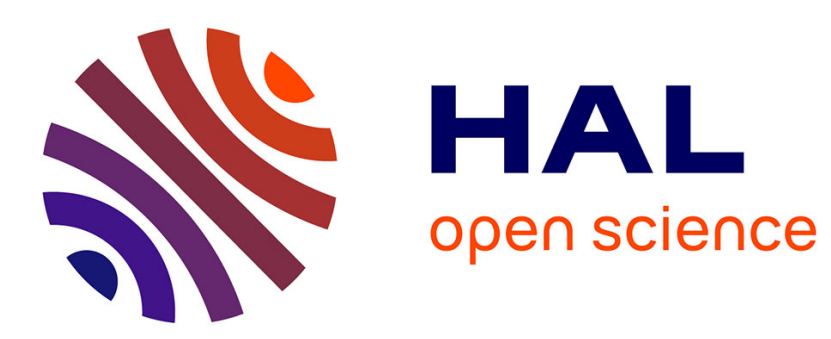

\title{
First-principle based modeling of urea decomposition kinetics in aqueous solutions
}

André Nicolle, Stefania Cagnina, Theodorus de Bruin

\section{To cite this version:}

André Nicolle, Stefania Cagnina, Theodorus de Bruin. First-principle based modeling of urea decomposition kinetics in aqueous solutions. Chemical Physics Letters, 2016, 664, pp.149-153. 10.1016/j.cplett.2016.10.032 . hal-01449373

\section{HAL Id: hal-01449373 https://hal.science/hal-01449373}

Submitted on 30 Jan 2017

HAL is a multi-disciplinary open access archive for the deposit and dissemination of scientific research documents, whether they are published or not. The documents may come from teaching and research institutions in France or abroad, or from public or private research centers.
L'archive ouverte pluridisciplinaire HAL, est destinée au dépôt et à la diffusion de documents scientifiques de niveau recherche, publiés ou non, émanant des établissements d'enseignement et de recherche français ou étrangers, des laboratoires publics ou privés. 


\section{First-principle Based Modeling of Urea Decomposition \\ 2 Kinetics in Aqueous Solutions}

3 André Nicolle ${ }^{1, *}$, Stefania Cagnina ${ }^{1}$, Theodorus de Bruin ${ }^{2}$

$4{ }^{1}$ Powertrain and Vehicle Division, IFP Energies Nouvelles, 1 et 4 avenue de Bois-Préau, 592852 Rueil-Malmaison Cedex, France; Institut Carnot IFPEN Transports Energie, France

$6{ }^{2}$ Applied Chemistry and Physical Chemistry Division, IFP Energies Nouvelles, 1 et 4 avenue 7 de Bois-Préau, 92852 Rueil-Malmaison Cedex, France

$8 *$ Corresponding author : andre.nicolle@ifpen.fr, Phone : +33 147526688

$9 \quad$ Keywords

10 Urea, decomposition, multiscale modeling, kinetics, ab initio, water cooperation

11 Abstract

12 This study aims at validating a multi-scale modeling methodology based on an implicit 13 solvent model for urea thermal decomposition pathways in aqueous solutions. The influence 14 of the number of cooperative water molecules on kinetics was highlighted. The obtained 15 kinetic model is able to accurately reproduce urea decomposition in aqueous phase under a 16 variety of experimental conditions from different research groups. The model also highlights 17 the competition between HNCO desorption to gas phase and hydrolysis in aqueous phase, 18 which may influence SCR depollution process operation. 


\section{Introduction}

Urea decomposition kinetics is important for a vast variety of applications, including agriculture [1], medical technologies [2] and energy [3]. In lean-burn automotive exhaust aftertreatment systems, a urea-water solution is injected upstream of the deNOx catalyst to generate ammonia for the selective catalytic reduction (SCR) process. Previous studies showed that urea aqueous phase decomposition can compete effectively with water evaporation rate [4] and urea polymerization [5]. While a number of recent studies [6] [7] contributed to the elucidation of main urea decomposition pathways in aqueous solution, the mechanism of ammonia and isocyanic acid release remains insufficiently understood, although a molecular mechanism for the homolytic breaking of $\mathrm{C}-\mathrm{N}$ bond seems more plausible than an ionic one [8]. Among the homolytic decomposition channels identified (ammonia elimination, hydrolysis and tautomerization), Alexandrova and Jorgensen [6] found the first path to have the lowest activation energy, partly resulting from the resonance stabilization in the first transition state. However, their study mainly focused on the solvent effects on the potential energy surface (PES), but not on the corresponding kinetic rate constants. These authors did not investigate the subsequent hydrolysis of isocyanic acid leading to an additional ammonia production. In the present study, we demonstrated the feasibility of a multiscale first-principle based kinetic modeling of urea decomposition in aqueous solution. We performed a high-level electronic structure study on the main ammonia production paths from urea decomposition including an implicit solvent model. Based on these new results, we herein derived the corresponding phenomenological rate constants and thermokinetic data to build a macrokinetic mechanism, which was subsequently validated against experimental data, allowing rate-of-production studies of urea decomposition under realistic operating conditions. 


\section{Methodology}

The electronic structure calculations were performed with the Gaussian 09 suite of programs [9]. All geometry optimizations were performed at the M06-2X/6-311++G(d,p) level of theory to correctly describe long-range hydrogen bonding [10]. Systematic conformational searches were performed to identify the most stable structures. The T1 diagnostic for all species involved in this work was less than 0.02, supporting the appropriateness of singlereference methods in describing the wave function. Frequency calculations confirmed the desired character of the stationary points and IRC calculations effectively ensured the connection between the reactants and products. In DFT calculations, we used the SMD implicit solvent model [11], which is known to produce errors for solvation energies typically lower than $1 \mathrm{kcal} / \mathrm{mol}$ for neutral molecules. Post Hartree-Fock energies were determined for the most important reaction steps by performing $\operatorname{CCSD}(\mathrm{T}) /$ aug-cc-pVTZ evaluations using Molpro 2015 program [12] on the geometries previously optimized at the DFT level. The ZPE-corrected Gibbs free energy was evaluated using the following formula:

$$
G=\mathrm{E}(C C S D(T) / / D F T)+G_{\text {corr }}(D F T)+\Delta E_{\text {solvation, } D F T, 0 K}
$$

In this equation $E$ refers to the electronic energy and $G_{c o r r}$ to the thermal corrections to the Gibbs Free energy, which envelopes the ZPE correction together with the translational, rotational and vibrational enthalpic and entropic corrections, calculated using M06-2X at the desired pressure and temperature. $\Delta E_{\text {solvation }}$ corresponds to the gas-to-water solvation energy, calculated at the M06-2X level without any thermal correction.

The harmonic transition state theory was selected to compute the corresponding phenomenological rate constants. Wigner correction factors [13] were computed to account for tunneling effects. Free activation energies were computed over the 300-600 K temperature range to get phenomenological rate constants in the Arrhenius-Kooij form 
$70 \quad k=A\left(\frac{T}{1 K}\right)^{n} \exp \left(-\frac{E}{R T}\right)$. Macrokinetic modeling was carried out using the homogeneous

71 (CSTR) reactor model implemented in Chemkin software package [14]. The same condensed72 phase mean-field macrokinetic formalism was used as in our previous work [4]. The reverse 73 rate constants were computed from the corresponding forward ones and reaction Gibbs free 74 energies. The Weizmann-1 (W1) theory [15] was used to determine the enthalpies of the energetic minima of the PES over the $300-600 \mathrm{~K}$ range and the obtained thermochemical data were implemented in the mechanism using the NASA formalism [16]. As can be seen in Table S1 (supplementary material), W1 theory coupled to SMD solvation model accurately predicts the available experimental thermochemical data, demonstrating its suitability for the present bottom-up kinetic modeling approach. Desorption rates were modeled from recommended [17] sticking coefficients $\left(0.1\right.$ for $\mathrm{NH}_{3}, \mathrm{HNCO}$ and $\left.\mathrm{CO}_{2}\right)$ using Hertz-Knudsen equation and equilibrium constants evaluated from thermochemical data.

\section{Results and discussion}

Our electronic structure calculations confirm, referring to the work of Jorgensen [6], that water-assisted $\mathrm{NH}_{3}$ elimination has a lower free energy of activation than hydrolysis (Figure $\mathrm{S} 1$ in supplementary material). As shown in Table 1, the Gibbs free energy barriers at $300 \mathrm{~K}$ and 1 atm for $\mathrm{NH}_{3} \mathrm{CONH}$ (Int 2) formation through water-assisted $\mathrm{H}$-shuttling lie at 30.9 and $30.3 \mathrm{kcal} / \mathrm{mol}$ for respectively one and two $\mathrm{H}_{2} \mathrm{O}$ molecules involved, in good agreement with the values obtained by Tsipis [23], Alexandrova [6] and Yao [7] (respectively 29.5, 26.4 and $25.3 \mathrm{kcal} / \mathrm{mol})$. The Free energy barrier associated to nucleophilic attack of water on carbonyl is much higher than this value, favoring $\mathrm{NH}_{3}$ elimination over urea hydrolysis. It is important to note that relative DFT energies can differ from post-HF values by up to $10 \mathrm{kcal} / \mathrm{mol}$ 
93 (Figure 2), which highlights the importance of a fine description of the electron correlation to

95

\begin{tabular}{|c|c|c|c|c|c|c|c|c|c|}
\hline \multicolumn{2}{|c|}{ Urea $+\mathrm{H}_{2} \mathrm{O} \rightarrow \mathrm{NH}_{3}+\mathrm{HNCO}+\mathrm{H}_{2} \mathrm{O}$} & \multicolumn{2}{c|}{$\begin{array}{c}\text { Urea }+2 \mathrm{H}_{2} \mathrm{O} \rightarrow \\
\mathrm{NH}_{3}+\mathrm{HNCO}+2 \mathrm{H}_{2} \mathrm{O}\end{array}$} & \multicolumn{2}{c|}{$\begin{array}{c}\mathrm{HNCO}+\mathrm{H}_{2} \mathrm{O}+\mathrm{NH}_{3} \\
\rightarrow \mathrm{NH}_{2} \mathrm{COOH}+\mathrm{NH}_{3}\end{array}$} & \multicolumn{2}{c|}{$\begin{array}{c}\mathrm{HNO}+2 \mathrm{H}_{2} \mathrm{O} \rightarrow \\
\mathrm{NH}_{2} \mathrm{COOH}+\mathrm{H}_{2} \mathrm{O}\end{array}$} \\
\hline complex & TS1 & Int2 & TS2 & complex & TS1 & complex & TS3 & complex & TS3 \\
\hline 4.1 & 35.0 & 28.2 & 38.2 & 14.5 & 44.8 & 11.0 & 30.6 & 12.2 & 36.0 \\
\hline
\end{tabular}

96

Table 1 - Relative Gibbs Free energies at $300 \mathrm{~K}$ and $1 \mathrm{~atm}$ with respect to the reactants

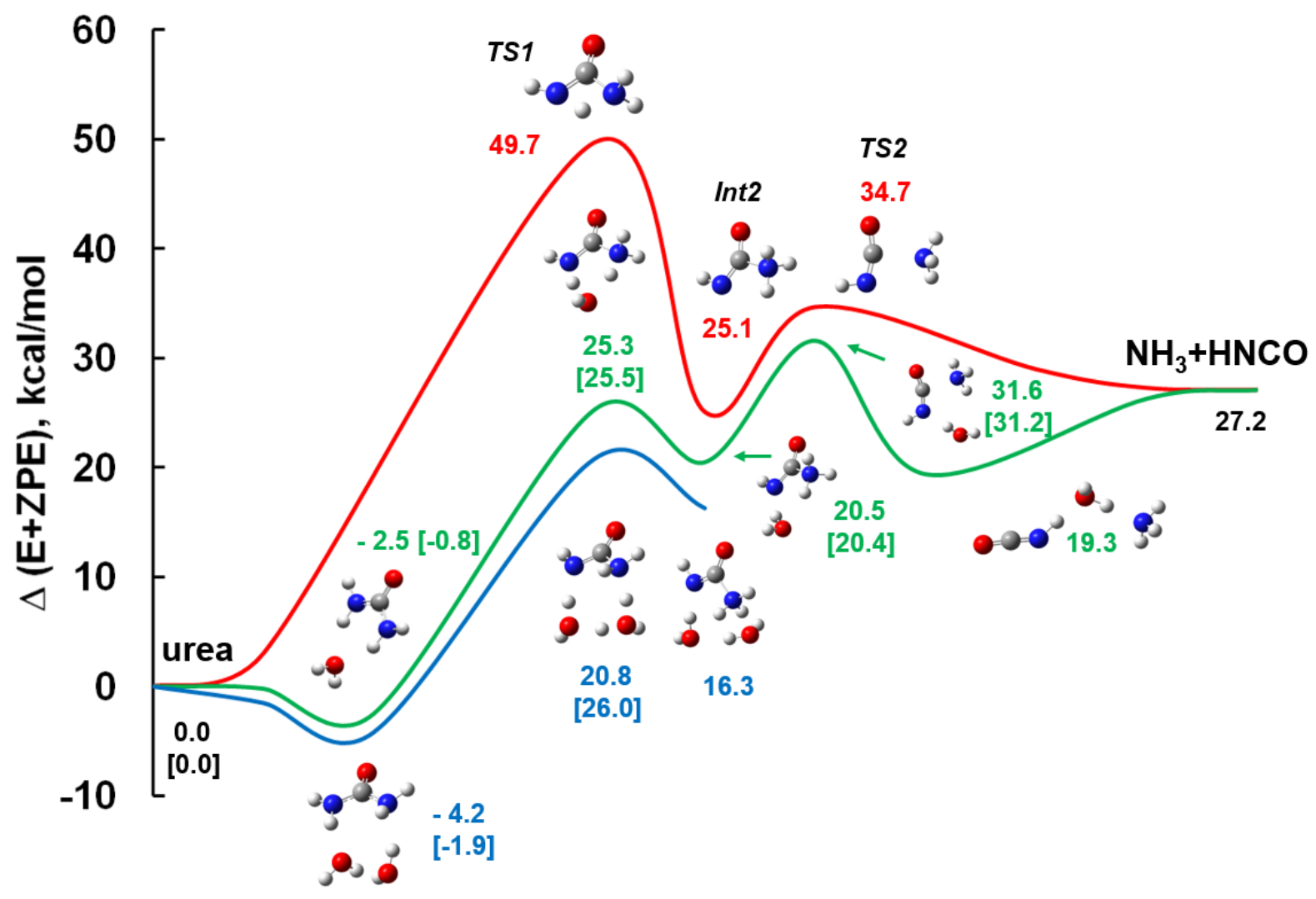

Figure 1 - Relative ZPE-corrected electronic energies (in kcal/mol) obtained at the M06-2X and CCSD(T)//M06-2X levels (in brackets) for unimolecular and water-assisted $\mathrm{NH}_{3}$ elimination. Red, green and blue curves correspond respectively to zero, one and two assisting water molecules. Since the energy potential for $\mathrm{C}-\mathrm{N}$ bond fission is weakly dependent on water involvement, this step was not studied in presence of $2 \mathrm{H}_{2} \mathrm{O}$ molecules. 
104 The subsequent hydrolysis of HNCO (Figure 2) proceeds through the formation of carbamic

105 acid, which can in turn decompose through either intramolecular or assisted mechanism. In 106 the present study, we focused on the addition of water across the $\mathrm{C}=\mathrm{N}$ bond of $\mathrm{HNCO}$, as it is 107 energetically more favorable [24] than addition across the $\mathrm{C}=\mathrm{O}$ bond due to the extended 108 concentration of the electron density on nitrogen [25]. Although a competitive bicarbonate 109 mechanism could also be considered in this study, it is not expected to change HNCO 110 hydrolysis kinetics since the transition state (TS) structures involved are very similar [26]. As 111 could be anticipated [27], the six-membered-ring TS involving two water molecules results in 112 a lower barrier $(19.7 \mathrm{kcal} / \mathrm{mol})$ compared to a four-membered-ring TS $(38.9 \mathrm{kcal} / \mathrm{mol})$. 113 According to Wei et al. [24], the former barrier lies less than $4 \mathrm{kcal} / \mathrm{mol}$ from the value 114 obtained by considering an eight-membered cyclic TS, showing the fast convergence of this 115 barrier with the number of water molecules. Interestingly, water addition assisted by ammonia 116 (instead of water) shows a significantly lower energetic barrier. 


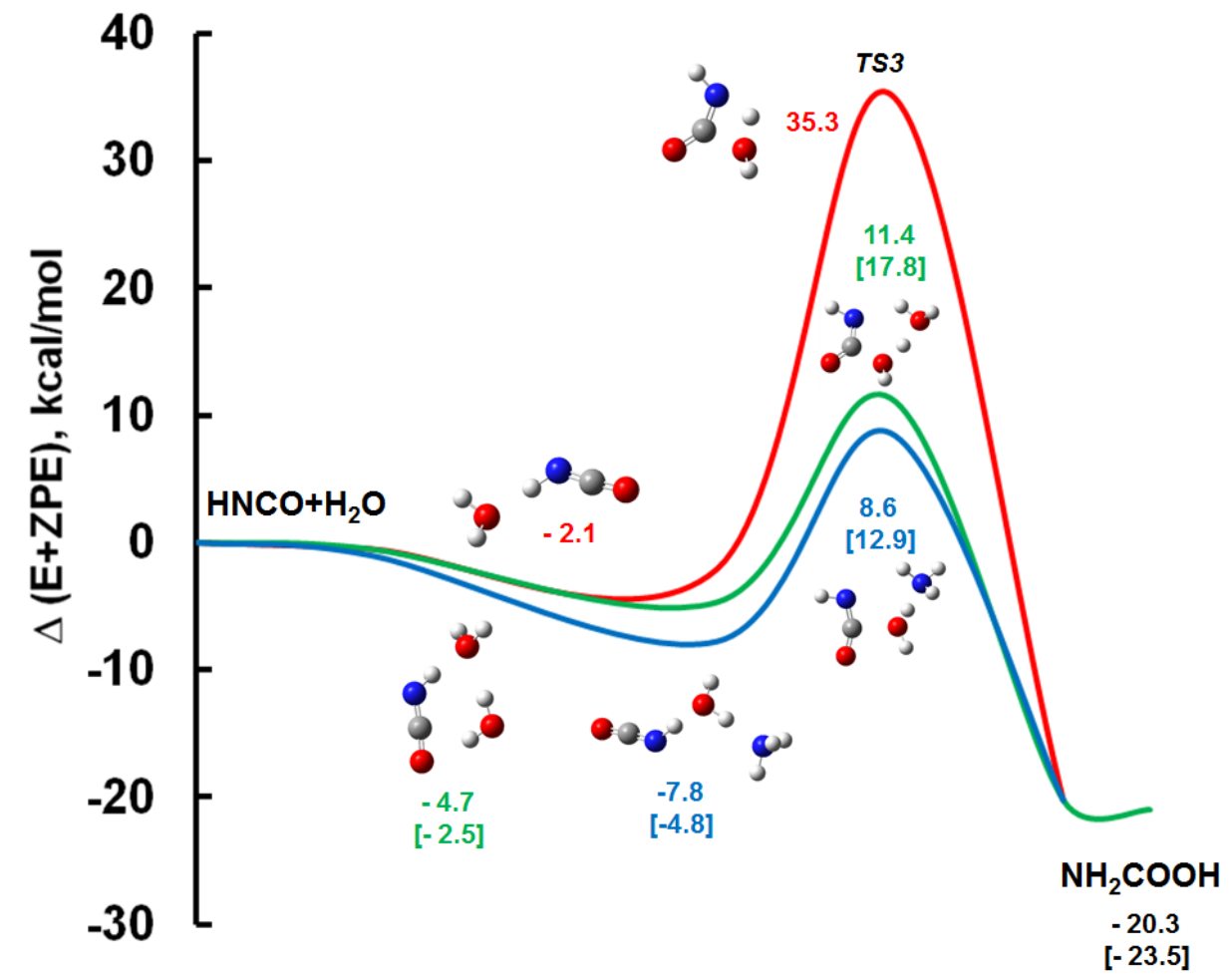

Figure 2 - Relative ZPE-corrected electronic energies (in kcal/mol) obtained at the M06-2X and CCSD(T)//M06-2X levels (in brackets) for HNCO hydrolysis. Red, green and blue curves correspond respectively to zero, one water and one ammonia assisting molecules.

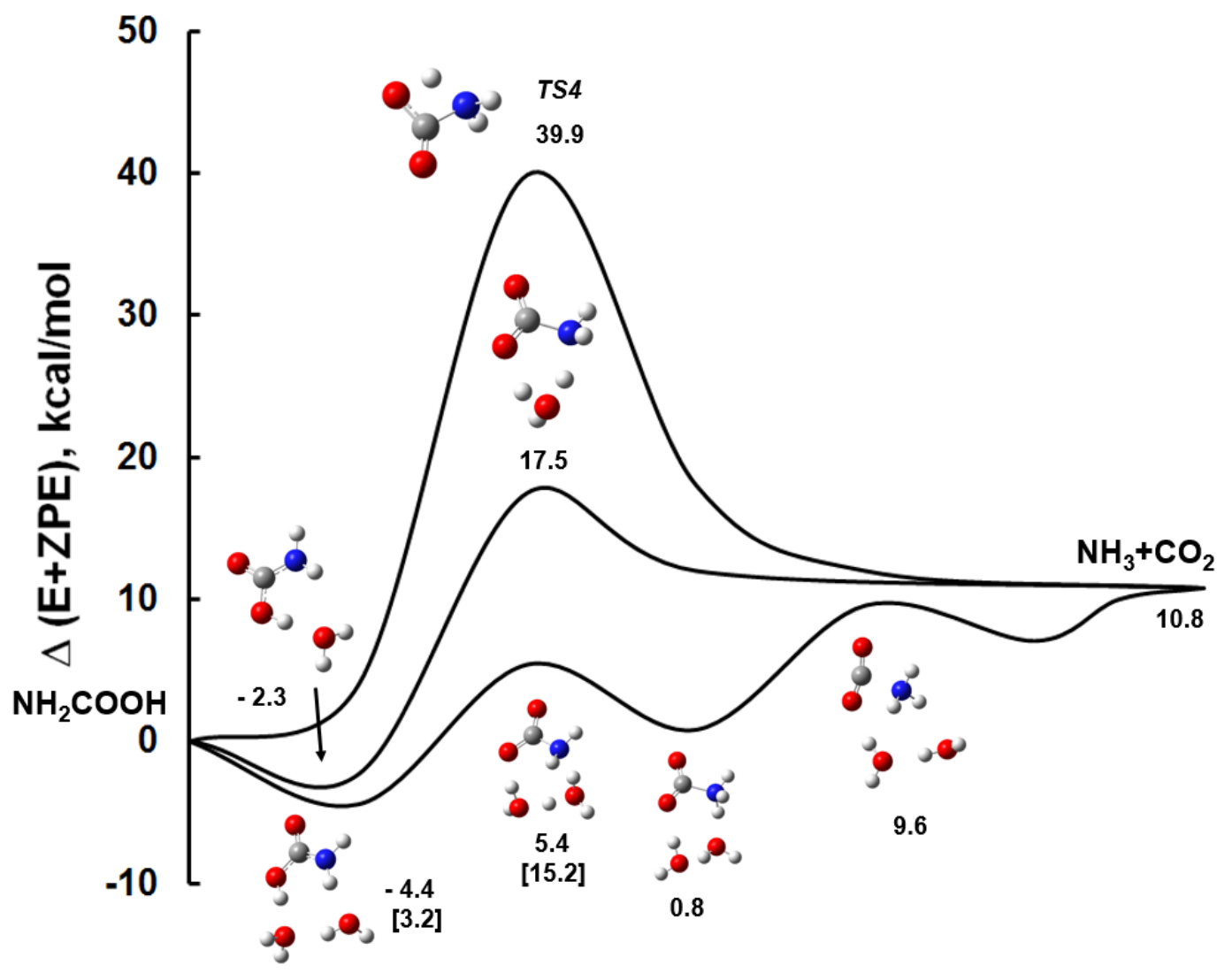

Figure 3 - Relative ZPE-corrected electronic energies (in kcal/mol) obtained at the M06-2X and CCSD $(\mathrm{T}) / / \mathrm{M} 06-2 \mathrm{X}$ levels (in brackets) for $\mathrm{NH}_{3}$ elimination from carbamic acid. 
As can be seen on Figure 3, the energetic barriers for carbamic acid decarboxylation are also highly dependent on the number of water molecules involved. As for HNCO, the attack of one water molecule on $\mathrm{C}=\mathrm{N}$ bond (barrier of $19.8 \mathrm{kcal} / \mathrm{mol}$ ) is more favorable than an attack of water on $\mathrm{C}=\mathrm{O}$ bond (barrier of $27.5 \mathrm{kcal} / \mathrm{mol}$ reported in [28]). The geometry of the sixmembered cyclic TS (obtained by considering one water molecule) is globally similar to the gas-phase TS described by Tsipis et al. [29], although water's oxygen lies clearly out-of-plane (respective OCNO dihedral angles of $7.2^{\circ}$ and $32.0^{\circ}$ ). Note also that this H-shuttling mechanism is similar to that reported by Ramachandran [30] for ammonia-assisted decomposition of carbamic acid in dry medium, who obtained a Free energy barrier of 18 $\mathrm{kcal} / \mathrm{mol}$, in contrast with Cheng et al. [31] who considered a four-membered ring TS structure, thereby leading to a barrier similar to that of the unassisted decarboxylation. As the number of water molecules increases, an additional local minimum appears in the energetic potential. The energetic barrier obtained in the case of the assistance of two water molecules $(12.0 \mathrm{kcal} / \mathrm{mol})$ is significantly lower than the reported value of $15.0 \mathrm{kcal} / \mathrm{mol}$ previously obtained at a lower level of theory (with only one water molecule) by Ruelle et al. [32] and the experimental value $(15.6 \mathrm{kcal} / \mathrm{mol})$ reported by Wang et al. [33] However, it is in good agreement with the barrier of $10.3 \mathrm{kcal} / \mathrm{mol}$ recently claimed by Noble et al. [34] in the presence of $6 \mathrm{H}_{2} \mathrm{O}$ molecules. 

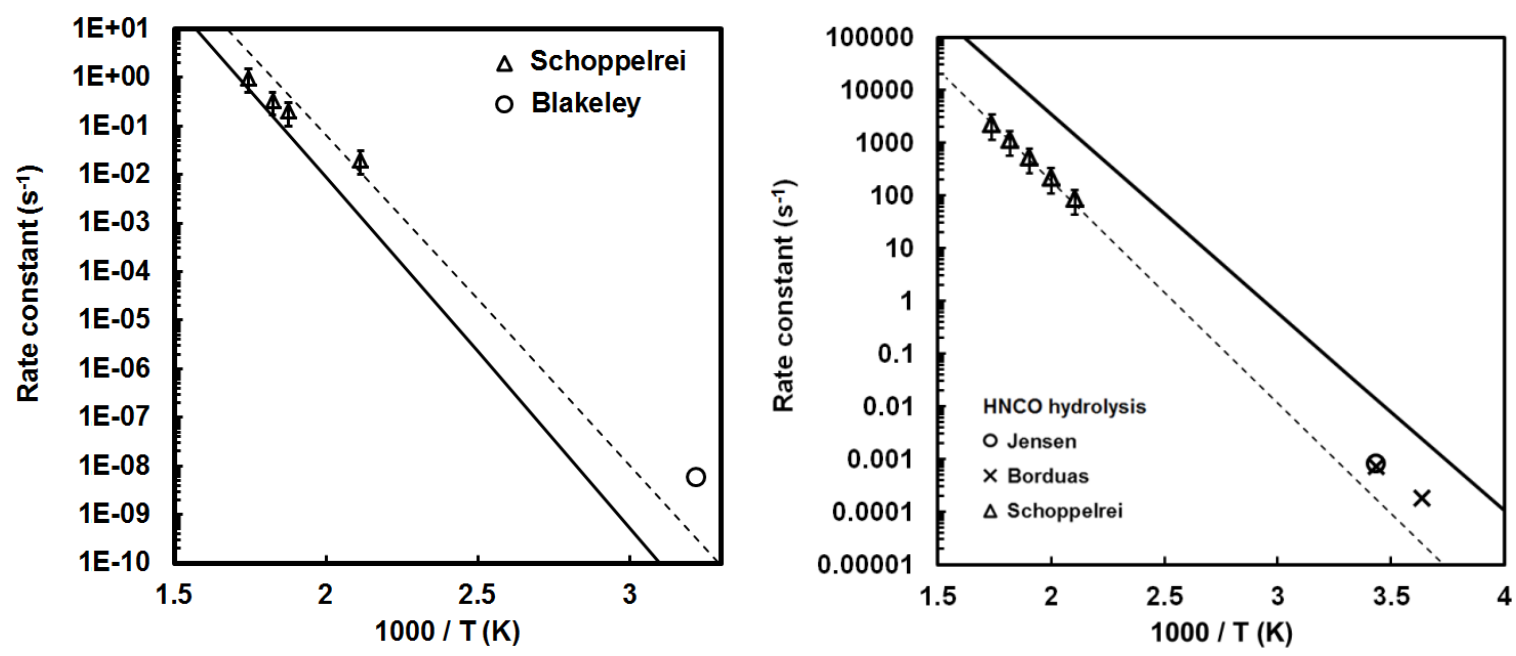

Figure 4 - Calculated and measured [35] [20] [36] [37] [38] rate constants for ammonia elimination from urea (left) and $\mathrm{HNCO}$ hydrolysis (right) in water solution. For $\mathrm{NH}_{3}$ elimination, the quasi-steady state approximation (QSS) on Int2 ( $\left.\mathrm{NH}_{3} \mathrm{CONH}\right)$ is applied (see text). The dotted line on the left denotes the ab initio rate constant with an activation energy decreased by $2 \mathrm{kcal} / \mathrm{mol}$. The dotted line on the right corresponds to the ab initio rate constant including Kramers barrier recrossing correction and with an activation energy increased by 2 $\mathrm{kcal} / \mathrm{mol}$.

Rate constant calculations for the most favorable reaction pathways were subsequently performed to derive phenomenological rate constants from the multi-well free energy surface. Arrhenius-Kooij least-squares fits on calculated rate constant values for most favorable waterassisted channels are provided in Table S2 (supplementary material). As can be noticed from the comparison with experimental data in Figure 4, within the uncertainties on molecular parameters, the present multi-scale approach is able to generate accurate rate coefficients (within a factor of 2) over an extended temperature range. Note that the rate constants of backward reaction Int $2 \rightarrow$ Urea $\left(3.08 \times 10^{09} \mathrm{~s}^{-1}\right.$ at $\left.500 \mathrm{~K}\right)$ and second step Int $2 \rightarrow \mathrm{NH}_{3}+$ $\mathrm{HNCO}\left(1.54 \times 10^{09} \mathrm{~s}^{-1}\right.$ at $\left.500 \mathrm{~K}\right)$ remain much higher than forward reaction Urea $\rightarrow \operatorname{Int} 2(2.04$ $\times 10^{-02} \mathrm{~s}^{-1}$ at $\left.500 \mathrm{~K}\right)$ over a wide range of temperatures, therefore Int2 $\left(\mathrm{NH}_{3} \mathrm{CONH}\right)$ can be assumed to be in quasi steady state (QSS). Under these conditions, our calculations indicate 
163

1

that the rate-limiting step switches between Int $\rightarrow \mathrm{NH}_{3}+\mathrm{HNCO}$ at $\mathrm{T}<600 \mathrm{~K}$ and Urea $\rightarrow$ Int2 at $\mathrm{T}>600 \mathrm{~K}$ [39]. It is also worth noting that except for very high urea concentrations in water solution $(>10 \mathrm{M})$, intrinsic reaction kinetics is not expected to be limited by cage diffusion $\left(4 \pi \sigma D_{\text {urea } / \text { water }} N_{A} C_{\text {urea }} \sim 10^{10} \mathrm{~s}^{-1}\right)$ at temperatures of interest $(\mathrm{T}<1000 \mathrm{~K})$ [40].

Even though the rate constant is mostly sensitive to the TS1 relative electronic energy (Figure S2 in supplementary material), the sensitivity to vibrational and rotational partition functions of TS1 (respectively through frequencies and moments of inertia) is significant. As the error on the herein obtained vibrational frequencies is typically of the order of a few percent and since anharmonicity is not accounted for in this study, a significant uncertainty (>10\%) remains on the partition function.
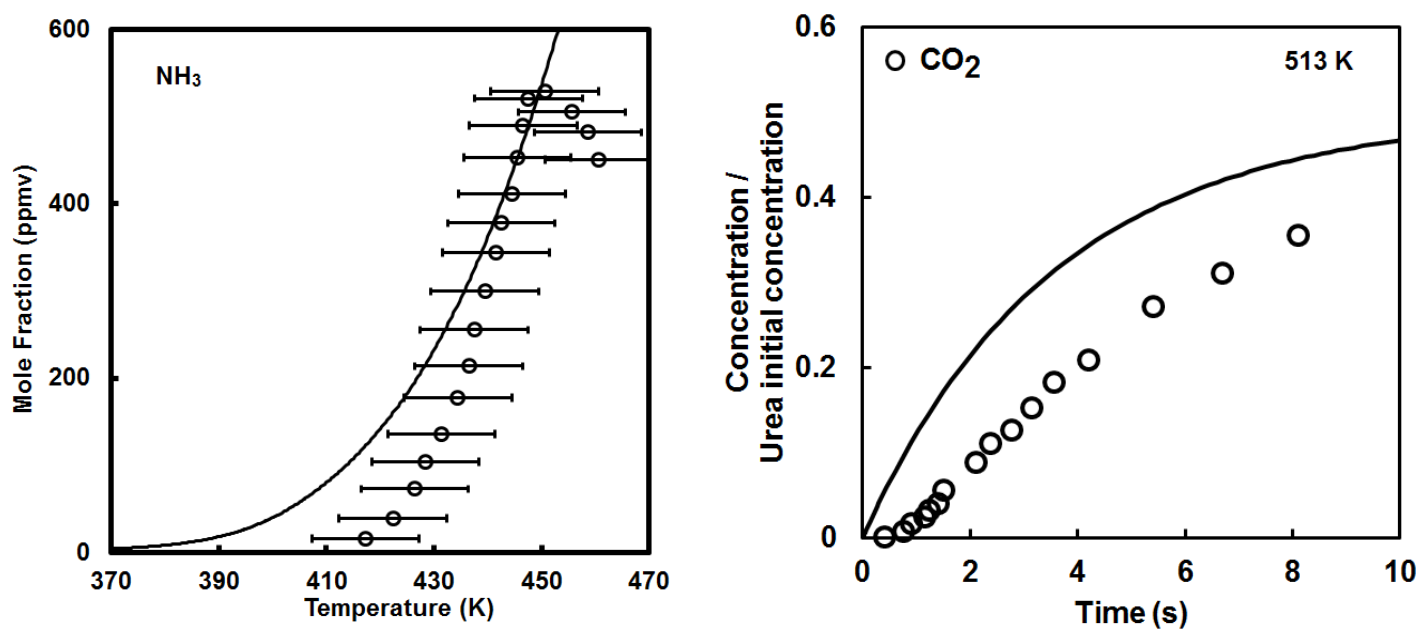

Figure 5 - On the left, calculated (lines) and measured (symbols) species gas-phase $\mathrm{NH}_{3}$ mole fraction, where the experimental uncertainty was deduced from reproducibility tests carried out by the authors[41]. On the right, the $\mathrm{CO}_{2}$ liquid-phase mole fraction profiles during urea-water solution decomposition. [37] 
Figure 5 shows ammonia concentration profiles obtained using the $a b$ initio kinetic model

181 (Table S2, supplementary material). This model reproduces well the onset of $\mathrm{NH}_{3}$ release, but 182 it tends to overestimate the ammonia concentration at temperatures higher than $470 \mathrm{~K}$. This 183 can be attributed to the concurrent formation of biuret $\left(\mathrm{NH}_{2} \mathrm{C}(\mathrm{O}) \mathrm{NHC}(\mathrm{O}) \mathrm{NH}_{2}\right)$ from urea and $184 \mathrm{HNCO}$, which is not accounted for by the present kinetic model. In Lundström's experimental 185 conditions [41], our reaction flux analyses at $400 \mathrm{~K}$ indicate that HNCO hydrolysis rate in 186 aqueous phase contributes to $35 \%$ of $\mathrm{HNCO}$ consumption while HNCO desorption to gas 187 phase represents $65 \%$ of its consumption. Therefore, according to this model, HNCO 188 hydrolysis is expected to contribute significantly to $\mathrm{NH}_{3}$ production in SCR process 189 conditions.

190 Note that urea selectivity to $\mathrm{CO}_{2}$ formation is also well predicted by the present ab initio

kinetic model (Figure 5). Further, the present model predicts that the carbamic acid maximum mole fraction in aqueous solution should be of the order of $1 \mathrm{ppm}$ under urea decomposition conditions, calling for quantitative measurements of this intermediate. Due to the high Free energy barrier involved, the contribution of urea hydrolysis should remain negligible under the investigated conditions, although it can be anticipated [4] [42] that higher heating rates would shift $\mathrm{NH}_{3}$ conversion profile towards higher temperatures, thereby favoring direct urea hydrolysis.

\section{Conclusions}

A multi-scale modeling methodology based on electronic structure calculations using an implicit solvent model, transition state theory and macrokinetic modeling was validated on the important issue of homolytic urea thermal decomposition in aqueous solutions. The influence of the number of cooperative water molecules on reaction kinetics was highlighted. The obtained macrokinetic model is able to reproduce urea decomposition in the aqueous phase 
under a variety of experimental conditions from different groups. The evidence of occurrence of urea decomposition in aqueous solution under typical SCR operating conditions should encourage engineers to include these hitherto neglected paths in their kinetic models [43].

Notably, the model reveals that HNCO hydrolysis in aqueous phase competes effectively with its desorption, providing evidence of the contribution of condensed phase HNCO hydrolysis during SCR process operation. While the present obtained thermokinetic data will allow more accurate modeling of industrial and biological systems, further work is needed to extend the model to urea polymerization in aqueous and dry media [44] [45] to get more accurate predictions of urea decomposition at higher temperatures.

\section{Acknowledgments}

SC would like to thank IFPEN for a post-doctoral grant. This research did not receive any other specific grant from funding agencies in the public, commercial or not-for-profit sector.

\section{Supporting information}

Additional informations including the geometries of the most important stationary points obtained in the present study are available as a supplementary material.

\section{References}

[1] M.L. Cabrera, D.E. Kissel, B.R. Bock, Soil Biology and Biochemistry 23 (1991) 1121.

[2] D. El-Gamal, S.P. Rao, M. Holzer, S. Hallstrom, J. Haybaeck, M. Gauster, C. Wadsack, A. Kozina, S. Frank, R. Schicho, R. Schuligoi, A. Heinemann, G. Marsche, Kidney international 86 (2014) 923.

[3] R. Rota, D. Antos, É.F. Zanoelo, M. Morbidelli, Chemical Engineering Science 57 (2002) 27.

[4] V. Ebrahimian, A. Nicolle, C. Habchi, AIChE Journal 58 (2012) 1998.

[5] P.M. Schaber, J. Colson, S. Higgins, D. Thielen, B. Anspach, J. Brauer, Thermochimica Acta 424 (2004) 131.

[6] A.N. Alexandrova, W.L. Jorgensen, The Journal of Physical Chemistry. B 111 (2007) 720.

[7] M. Yao, X. Chen, C.-G. Zhan, Chemical Physics Letters 625 (2015) 143.

[8] J. Shorter, Chemical Society Review 7 (1978) 1.

[9] M. J. Frisch, G. W. Trucks, H. B. Schlegel, G. E. Scuseria, M. A. Robb, J. R. Cheeseman, G. Scalmani, V. Barone, B. Mennucci, G. A. Petersson, H. Nakatsuji, M. Caricato, X. Li, H. P. Hratchian, A. F. Izmaylov, J. Bloino, G. Zheng, J. L. Sonnenberg, M. Hada, M. Ehara, K. Toyota, R. Fukuda, J. Hasegawa, M. Ishida, T. 
Nakajima, Y. Honda, O. Kitao, H. Nakai, T. Vreven, Montgomery, Jr., J. A., J. E. Peralta, F. Ogliaro, M. Bearpark, J. J. Heyd, E. Brothers, K. N. Kudin, V. N. Staroverov, R. Kobayashi, J. Normand, K. Raghavachari, A. Rendell, J. C. Burant, S. S. Iyengar, J. Tomasi, M. Cossi, N. Rega, J. M. Millam, M. Klene, J. E. Knox, J. B. Cross, V. Bakken, C. Adamo, J. Jaramillo, R. Gomperts, R. E. Stratmann, O. Yazyev, A. J. Austin, R. Cammi, C. Pomelli, J. W. Ochterski, R. L. Martin, K. Morokuma, V. G. Zakrzewski, G. A. Voth, P. Salvador, J. J. Dannenberg, S. Dapprich, A. D. Daniels, Ö. Farkas, J. B. Foresman, J. V. Ortiz, J. Cioslowski, D. J. Fox, Gaussian 09. [10]Y. Zhao, D.G. Truhlar, Theor Chem Account 120 (2008) 215.

[11]A.V. Marenich, C.J. Cramer, D.G. Truhlar, The Journal of Physical Chemistry. B 113 (2009) 6378.

[12]H.-J. Werner, P.J. Knowles, G. Knizia, F.R. Manby, M. Schütz, WIREs Comput Mol Sci 2 (2012) 242.

[13]E. Wigner, Z Phys Chem B-Chem E 19 (1932) 203.

[14]E. Meeks, H.K. Moffat, J.F. Grcar, R.J. Kee, Sandia National Laboratories Report SAND96-8218 (1996).

[15]J.M.L. Martin, G. de Oliveira, Journal of Chemical Physics. 111 (1999) 1843.

[16]S. Gordon, B.J. McBride, NASA SP-273 168 (1971).

[17]M. Ammann, R.A. Cox, J.N. Crowley, M.E. Jenkin, A. Mellouki, M.J. Rossi, J. Troe, T.J. Wallington, Atmospheric Chemistry and Physics. 13 (2013) 8045.

[18]A.V. Kustov, N.L. Smirnova, Journal of Chemical \& Engineering Data. 55 (2010) 3055.

[19]C.E. Vanderzee, D.L. King, The Journal of Chemical Thermodynamics 4 (1972) 675

[20]N. Borduas, B. Place, G.R. Wentworth, J.P.D. Abbatt, J.G. Murphy, Atmospheric Chemistry and Physics. 16 (2016) 703 .

[21]J.J. Carroll, J.D. Slupsky, A.E. Mather, Journal of Physical and Chemical Reference Data. 20 (1991) 1201.

[22]M.W. Chase, NIST-JANAF thermochemical tables, American Chemical Society; American Institute of Physics for the National Institute of Standards and Technology, Woodbury, N.Y., 1998.

[23]C.A. Tsipis, P.A. Karipidis, Journal of the American Chemical Society 125 (2003) 2307.

[24]X.-G. Wei, X.-M. Sun, X.-P. Wu, S. Geng, Y. Ren, N.-B. Wong, W.-K. Li, Journal of Molecular Modeling 17 (2011) 2069.

[25]Greet Raspoet, and Minh Tho Nguyen, Michelle McGarraghy, and Anthony Frank Hegarty, The Journal of Organic Chemistry 63 (1998) 6867.

[26]T.R. Prosochkina, E.L. Artem'eva, E.A. Kantor, Russian Journal of General Chemistry. 83 (2013) 10.

[27]S. Tolosa Arroyo, A. Hidalgo Garcia, J.A. Sanson Martin, The Journal of Physical Chemistry A. 113 (2009) 1858.

[28]D.Y. Kim, H.M. Lee, S.K. Min, Y. Cho, I.-C. Hwang, K. Han, J.Y. Kim, K.S. Kim, The Journal of Physical Chemistry Letters. 2 (2011) 689.

[29]C.A. Tsipis, P.A. Karipidis, The Journal of Physical Chemistry A. 109 (2005) 8560.

[30]B.R. Ramachandran, A.M. Halpern, E.D. Glendening, The Journal of Physical Chemistry A 102 (1998) 3934.

[31]X. Cheng, Y. Zhao, W. Zhu, Y. Liu, Journal of Molecular Modeling 19 (2013) 5037.

[32]P. Ruelle, U.W. Kesselring, N.-T. Hô, Journal of Molecular Structure: THEOCHEM 124 (1985) 41.

[33]X. Wang, W. Conway, D. Fernandes, G. Lawrance, R. Burns, G. Puxty, M. Maeder, The Journal of Physical Chemistry A 115 (2011) 6405.

[34]J.A. Noble, P. Theule, F. Duvernay, G. Danger, T. Chiavassa, P. Ghesquiere, T. Mineva, D. Talbi, Physical Chemistry Chemical Physics : PCCP 16 (2014) 23604.

[35]M.L. Kieke, J.W. Schoppelrei, T.B. Brill, The Journal of Physical Chemistry. 100 (1996) 7455.

[36]M.B. Jensen, W. Taub, D. Ginsburg, K. Hartiala, S. Veige, E. Diczfalusy, Acta Chemica Scandinavica. 12 (1958) 1657.

[37]J.W. Schoppelrei, M.L. Kieke, X. Wang, M.T. Klein, T.B. Brill, The Journal of Physical Chemistry. 100 (1996) 14343.

[38]R.L. Blakeley, A. Treston, R.K. Andrews, B. Zerner, Journal of the American Chemical Society 104 (1982) 612.

[39]J.R. Murdoch, Journal of Chemical Education 58 (1981) 32. 
[40]L.S. Sorell, A.S. Myerson, AIChE Journal 28 (1982) 772.

[41]A. Lundström, B. Andersson, L. Olsson, Chemical Engineering Journal 150 (2009) 544.

[42]S.A. Skarlis, A. Nicolle, D. Berthout, C. Dujardin, P. Granger, Thermochimica Acta 584 (2014) 58.

[43]F. Birkhold, U. Meingast, P. Wassermann, O. Deutschmann, Applied Catalysis B: Environmental 70 (2007) 119.

[44]W. Brack, B. Heine, F. Birkhold, M. Kruse, G. Schoch, S. Tischer, O. Deutschmann, Chemical Engineering Science 106 (2014) 1. 

Supplementary Materials
Click here to download Supplementary Materials: Supp_Mat_submitted.docx

Click here to download Supplementary Materials: Supp_Mat_submitted.docx

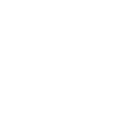

$\sqrt{2}$

$\sqrt{3}$

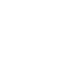

(1)

$\sqrt{3}$

(1)

(1) . . . . . . . . . . . . . . . .

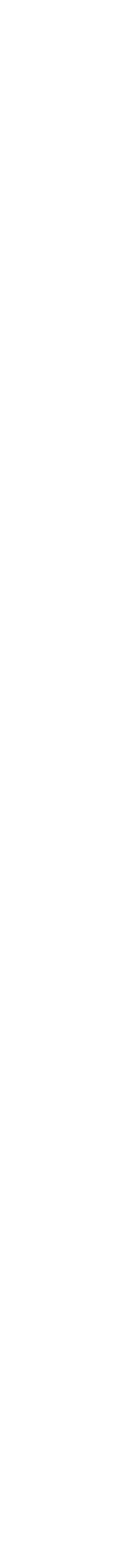

